\title{
A Grassroots, Practical Response to Student Belonging through Learning and Teaching Experiences
}

Wilson, Rachel; Murray, Gabrielle and Clarke, Bronwyn

Office of the Deputy Vice-Channcellor Education, Education Portfolio, RMIT University, Australia.

\begin{abstract}
RMIT University is Australia's second largest higher education provider and has a very diverse student body. Taking a holistic approach and capturing the entire student life cycle, the RMIT Belonging Strategy outlines a rationale and plan for delivering belonging interventions across the whole institution. An institution wide strategy requires economic, political and global considerations; however, as grass-roots academics, our work is informed by the philosophy that education can affect positive communitarian and individual change, and that meaningful and authentic relations with staff and students enable genuine collaboration and growth (Chickering, Dalton, \& Stamm, 2006; Kreber, 2013). Guided by these principles, we identified five drivers that impact student belonging at the university, and proposed a measurement framework to form an 'index' of belonging that can be tracked and reported. This paper focuses on the innovative and collaborative work of developing an enterprise wide strategy for inclusive belonging and presents a roadmap of the process. We argue that grassroots, practical responses through learning experience interventions have the greatest potential to influence student engagement.
\end{abstract}

Keywords: Belonging Strategy; grassroots; curriculum; learning experiences. 


\section{Introduction}

As an ethos, belonging is highly applicable to education, and work within RMIT University and the sector more broadly has identified that generating a sense of belonging for students has significant positive impact on transition and retention, learning outcomes, engagement, wellbeing and organisational advocacy (Tinto, 1993; Hurtado \& Carter, 1997; Walton, Cohen, Cwir, \& Spence, 2011; Strayhorn, 2012; Thomas, 2012; Morieson, Carlin, Clarke, Lukas, \& Wilson, 2013; Ribera, Miller, \& Dumford, 2017). A dual sector, tertiary institution, RMIT University is Australia's second largest university, with additional campuses in Vietnam and Spain. The university offers programs in vocational education and higher education, ranging from certificates through to postgraduate research degrees. In Melbourne, there are close to 60,000 students enrolled and the institution employs more than 5000 academic staff. The RMIT Belonging Strategy builds on the research of the Belonging Project (2011-2015), a four-year, multidisciplinary study, with the chief aim of improving student experience in the School of Media and Communication, at RMIT University (Clarke \& Wilson, 2016).

To give shape to an 'ideal' student experience in the School of Media and Communication, we developed a Belonging Narrative Model proposing a three-tier student experience, in line with the three-year structure of the undergraduate degree, to build students' sense of identity and engagement. Students began with a strong disciplinary and professional base before becoming more aware of their place within an interdisciplinary community as future professionals working in a wider world of global connections and experiences (Araujo, Wilson \& Clarke, 2015). We introduced five pilot initiatives focussing on orientation, transition, cohort building, student spaces and academic skills and literacies. An important outcome of the project was a prototype for de-identified data-packs for the purpose of providing staff with key socio-economic data on their cohorts. The data-pack initiative was specifically designed to provide evidence-based information aimed at encouraging teaching staff to provide tailored classroom experiences for all their students. The data-packs are now in general use for all teaching staff across RMIT university. Through a range of low cost, small-scale activities such as Cohort Day Out initiatives, coordinated Orientation Week activities and the co-creation of student informal spaces, the Belonging Project delivered a range of positive, discipline based interactions amongst student cohorts and between students and staff. Mix methods evaluation through surveys, focus groups and interviews has shown the initiatives provided a successful way to develop stronger connections amongst cohorts and significantly improved students' sense of belonging (for further discussion, see Morieson, Carlin, Clarke, Lukas, \& Wilson, 2013; Araujo, Wilson, \& Clarke, 2015; Clarke, \& Wilson, 2016). 
In 2017, we were invited to assess the feasibility of scaling up the Belonging Project's findings across the whole institution. To be sustainable, the project necessitated an institution wide strategy that required economic, political and global considerations. However, as grass-roots educators and academics, our work is guided by the principal that education can affect positive communitarian and individual change, and that meaningful and authentic relations with staff and students enable genuine collaboration and growth (Chickering, Dalton, \& Stamm, 2006; Kreber, 2013). Guided by this philosophy, the RMIT Belonging Strategy has emerged from an extensive internal stakeholder consultation process that has been underway since February 2017. The strategy identified five drivers that impact student belonging at RMIT, and proposed a measurement framework to form an 'index' of belonging that can be tracked and reported. This paper focuses on the collaborative work of developing an enterprise wide strategy for inclusive belonging, and the identification of five drivers of student belonging. We argue that grassroots, practical responses through learning interventions have the greatest potential to influence the student experience and impact learning engagement.

\section{Background}

Central to our conception of belonging has been Baumeister and Leary's (1995, p. 497) hypothesis that human beings are driven to form "significant interpersonal relationships". The failure to belong or to make human connections is closely associated with ill adjustment, poor health and a lack of well-being, consequently leading to feelings of "isolation, alienation, and loneliness" (Mellor, Stokes, Firth, Hayashi, \& Cummins, 2008, p. 213). Belonging is a fundamental human need that refers to "a feeling or sensation of connectedness" (Strayhorn, 2012, p. 4). Strayhorn (2012) has linked a sense of belonging to the transformative mission of higher education in the US, arguing that it should be considered a discrete theoretical concept within the higher education scholarship of learning and teaching. The concept's direct relationship to cognition and "achievement motivation" makes it a particularly useful in the domain of education (Strayhorn, 2012, p. 4). In higher education, belonging refers to the "experience of being important to the group" (Strayhorn, 2012, p. 17). It involves a reciprocal relationship between the individual and the group, which is dependent on the individual (e.g., Aboriginal and Torres Strait Islanders, international, local, rural, and low socioeconomic status students), the context (e.g., the classroom, clubs, campus), and the points at which students enter their studies. This means, as a need, belonging must be satisfied on a continual basis and is context-dependent.

In higher education, belonging has been closely linked to persistence and retention (Tinto, 1993; Hurtado \& Carter, 1997), and improved first-year student experiences (Kift, Nelson, \& Clarke, 2010; Krause, 2005; Morieson, Carlin, Clarke, Lukas, \& Wilson, 2013). In 2010, 
Kift, Nelson and Clarke named 'belonging' as one of three principles driving Queensland University of Technology's (QUT) innovative, whole-of-institution approach to the firstyear experience. Their approach acknowledged that engaging new learners in their learning requires awareness and access to support services, and "involvement, engagement and connectedness with their university experiences" (Kift et al., 2010, p. 4). Extensive work on belonging took place in the UK under the auspices of the Higher Education Funding Council for England, between 2008 to 2011, and encompassed seven discrete projects involving 22 higher education institutions (Thomas, 2012). The final report identified supportive peer relations, meaningful interaction between staff and students, developing knowledge, confidence and identity as successful higher education learners, and higher education experiences that are relevant to interests and future goals, as the means through which belonging can be successfully nurtured (Thomas, 2012). Supporting the Belonging Project's findings, the report stressed to improve engagement and success, it was necessary to embed a culture of belonging across whole institutions (Thomas, 2012; Clarke \& Wilson, 2016). The RMIT Belonging Strategy outlines a set of goals and interventions to activate an ethos of belonging across the entire student life cycle and beyond, while aligning and coordinate existing and new initiatives to ensure that change to the organisation is sustainable.

\section{A Holistic, Grassroots and Iterative Response}

As educators and researchers, our work is informed by action research methodology (Kemmis, 2007; Greenwood, Whyte, \& Harkavy, 1993), allowing us to reflexively study our own institutional setting. Following the iterative, reflexive and inclusive research method we established on the Belonging Project, we approached the development of the RMIT Belonging Strategy through techniques of co-creation to promote staff ownership and identified 'Champions', to ensure we had commitment to sustained and continuous engagement with staff at grassroots level. Between March and June 2017, we facilitated a rolling series of workshops and face to face meetings with academics, professional staff and executives to ascertain what a sense of belonging would look and feel like at RMIT. We developed a deeply consultative and iterative approach, where we regularly meet face-toface with stakeholders and kept them informed of the process. We had easy access to academic staff and solicited the opinions of Heads of Schools and Program Managers, seeking their advice about disciplinary belonging. Our Champions helped to negotiate meetings with executives, resulting in consultations with the ARG (Academic Register Group), Academic Support, who are responsible for industry and student mentoring, Communications, Governance, Marketing, HR (Human Resources), the Library, including the Study and Learning Centre, and Student Life, who deal with co and extra-curricular activities. Through this process, we also developed a complimentary working relationship 
with Ngarara Willim Centre at RMIT, which helped to conceptualise the importance of place within an ethos of belonging, and informed our thinking on how to improve Aboriginal and Torres Strait Islander students' learning experience.

To ensure we understood staffs' perceptions of belonging and the student experience we designed a Qualtrics online survey, which was emailed to all RMIT academic, executive and professional staff across the Melbourne campuses. The anonymous responses confirmed our perception that there is broad agreement among staff that belonging should be a focus for the organisation. An overwhelming majority of staff respondents $(n=642)$ indicated that they believe RMIT has a significant role to play in driving belonging for students. There was also broad consensus amongst staff; 94\% either "agree" or "strongly agree" that RMIT should be proactive in striving for a sense of belonging among students. The consultations we undertook also revealed that the tacit knowledge of staff is an essential tool in understanding the student experience within the university, and that interrogating and understanding the staff experience can assist to enhance the student experience. Sustained continuous engagement with staff at a grass-root level is essential if organisational change is to be achieved. This critical insight has proven common to all phases of our research, and affirms the recurring theme of the importance of harnessing the knowledge, expertise and resources of academic and professional staff, addressing their professional development needs and importantly, providing the support and requirement to sustain their commitment and participation (Clarke \& Wilson, 2016).

\subsection{Five Drivers of Student Belonging}

Before developing a range of interventions, we also surveyed our student body with the purpose of gaining a better understanding of what role the university should play in fostering a sense of belonging, and to identify opportunities for improvement. We developed a Qualtrics online Belonging Survey and employed students on a casual basis to administer the survey through a series of 'pop ups' across the three RMIT Melbourne campuses. The survey was also delivered online to all students attending the campuses. We advertised through Students Services and employed 10 students on a casual basis to work 3 and 4 hour shifts in the morning, afternoon and evening from the $18^{\text {th }}$ to the $26^{\text {th }}$ May at the City (38 hours), Brunswick (15 hours) and Bundoora (21 hours) campuses. Armed with touch screen iPads loaded with the survey, the students focussed on heavy traffic points such as the library entrances, informal student learning spaces, and eating areas. The survey captured 2780 responses (428 online, 2352 faces to face) during the consultation period and used a 5 level Likert scale for 6 questions, with a final open-ended question asking students to suggest "one thing" that RMIT could do to improve their sense of belonging. While research is still under way to unpack the qualitative data, other insights include that $84 \%$ of students surveyed believe that feeling respected and valued for their class contribution is either "somewhat important" or "extremely important". More than half of all respondents 
also said that feeling like they "fit in" with others in their discipline is "extremely important" (see Table 1) to their sense of belonging at RMIT University.

Table 1. Responses to question 'How important are the following experiences in making you feel like you belong at RMIT?' (N=2780)

\begin{tabular}{|c|c|c|c|c|}
\hline $\begin{array}{c}\text { Belonging } \\
\text { Driver }\end{array}$ & Survey Question & $\begin{array}{c}\text { Count of } \\
\text { 'somewhat } \\
\text { important' } \\
\text { Responses }\end{array}$ & $\begin{array}{c}\text { Count of } \\
\text { 'Extremely } \\
\text { Important' } \\
\text { Responses }\end{array}$ & $\begin{array}{l}\text { Driver } \\
\text { Weighting }\end{array}$ \\
\hline $\begin{array}{c}\text { Extra- } \\
\text { curricular } \\
\text { Activities }\end{array}$ & $\begin{array}{c}\text { Having opportunities to } \\
\text { participate in organized } \\
\text { activities outside my } \\
\text { formal classes }\end{array}$ & 1035 & 854 & $17.5 \%$ \\
\hline $\begin{array}{c}\text { Learning } \\
\text { Experiences }\end{array}$ & $\begin{array}{c}\text { Feeling like my teachers } \\
\text { respect me, and value } \\
\text { my contributions in } \\
\text { class }\end{array}$ & 1031 & 1398 & $25.5 \%$ \\
\hline $\begin{array}{c}\text { Physical and } \\
\text { Digital Spaces }\end{array}$ & $\begin{array}{c}\text { Having places around } \\
\text { campus where I can be } \\
\text { myself and interact with } \\
\text { my peers }\end{array}$ & 1148 & 1211 & $23.5 \%$ \\
\hline $\begin{array}{c}\text { Social } \\
\text { Networks }\end{array}$ & $\begin{array}{c}\text { Having gaod network } \\
\text { of friends who I've met } \\
\text { whilst studying at } \\
\text { RMIT }\end{array}$ & 1148 & 1211 & $23.5 \%$ \\
\hline $\begin{array}{c}\text { Student } \\
\text { Services }\end{array}$ & N/A & N/A & N/A & $10.0 \%$ \\
\hline
\end{tabular}

Student responses to our Belonging Survey together with other university student evaluations such as the Student Experience Survey (SES), Course Experience Questionnaire (CEQ), and Course Experience Surveys (CES) were used to determined weightings for a measurement framework to form an 'index' of belonging. We identify five drivers of student belonging: learning experiences, social networks, physical and digital spaces, extra-curricular activities and student services. The drivers are points of impact through which we can target interventions and expect to see a direct impact on attrition numbers, improvements in evaluations of the student experience, greater graduate satisfaction and an expansion of alumni numbers and participation. In responses to the survey, the area identified as having the highest weighting and therefore the greatest potential for impact around student engagement was "learning experiences" $25.5 \%$ (see table 1), with extracurricular activities and social networks following closely with a weighting each of $23.5 \%$. Both learning experiences and social networks are related to curriculum, whereas extracurricular activities, physical and digital spaces (17.5\%) and student services (10\%) drive organisational belonging. The RMIT Belonging Strategy seeks 
to measure and affect these drivers at different stages of the student journey, with the drivers informing our understanding of what a 'good' student experience of engagement at RMIT should look and feel like. These drivers are all factors over which RMIT can have some degree of influence, and it is through the lens of these drivers that we seek to measure and affect student belonging.

\subsection{Pilot Innovations: Belonging Program Workshops and Curriculum Specific Based Initiatives (CSBIs)}

Our research showed that the greatest impact we can have is in the area of learning experiences. Subsequently, we piloted several curricula based initiatives in 2017, including Belonging Program Workshops and Curriculum Specific Belonging Initiatives (CSBIs). These initiatives are examples of our top-down, bottom up approach. Facilitating workshops with program managers, academics and teaching staff allowed us to inform staff about the importance of fostering an ethos of belonging for their programs and to develop an accurate understanding of their changing student cohorts using a data lead methodology. Together we mapped current offerings for student, and identified further opportunities to enhance disciplinary belonging. We pinpointed best practice within the student space and established a 'to do' list of next steps. We also informed programs of targeted resources across unfamiliar parts of the university that could be better accessed to enhance students' experience.

The evaluations of our workshops where conclusively positive with one of the unexpected responses from staff being how much they relished the rare opportunity to come together as a whole program to discuss their class practice, share their ideas and successes and gain insights for new initiatives. These outcomes supported our decision to document CSBIs and to create a best practice resource. CSBIs are low cost, curriculum integrated activities which help students engage with each other, academic staff, and with their industry or profession. The resource is evolving with 52 case studies currently housed on the Belonging in Curriculum website. The purpose behind the resource is for staff to be inspired by their colleagues' work and adapt and model ideas. The CSBIs include early assessment with industry, field trips, website and App development and team building activities. The key aspect of each case study is their integration into the disciplinary content of the course or program they are servicing.

\section{Conclusion}

The RMIT Belonging Strategy articulates a vision for RMIT University to be known for its culture of belonging, where all students feel accepted, respected and valued. It outlines a set of goals and initiatives to help students develop a sense of connection to their organisation, 
and to their chosen discipline while they are enrolled as students, and to take with them a belonging mind-set into their future pathways. Of the five drivers identified through analysis of student evaluation data, we found that students consider their 'learning experiences" to be the most important and these are the experiences they have with their teachers, peers and industry mentors. We also discovered that engaging with staff at a grass-root level is essential if organisational change is to be achieved. Through developing a resource, the Belonging in the Curriculum website, we have begun to acknowledge the significant of their work as best practice in learning experiences and disciplinary belonging.

\section{References}

Araujo, N., Wilson, R., Clarke, B. (2015). Student engagement for employability: A

belonging project case study. Research and Development in Higher Education: Learning for life and work in a complex world, 38, 1-10.

Baumeister, R. F., \& Leary, M. R. (1995). The need to belong: desire for interpersonal attachments as a fundamental human motivation. Psychological Bulletin, 117(3), 497-529.

Chickering, A. W., Dalton, J. C., \& Stamm, L (2006). Encouraging Authenticity and Spirituality in Higher Education. San Francisco: Jossey-Bass.

Clarke, B., \& Wilson, R. (2016). The Ethos of Belonging: A Narrative Model Approach to Student Engagement 2011-2015. Melbourne, School of Media and Communications, RMIT University.

Greenwood, D. J., Whyte, W. F., \& Harkavy, I. (1993). Participatory action research as a process and as a goal. Human Relations, 46(2), 175-192.

Hurtado, S., \& Carter, D.F. (1997). Effects of college transition and perceptions of the

campus racial climate on Latino College students' sense of belonging. Sociology of Education. 70(4), 324-345.

Kemmis, S. (2007). Action Research. In M. Hammersley (Ed.), Educational Research and Evidence-based Practice (pp. 167-180). Milton Keynes and London: The Open University and SAGE Publications.

Kift, S., Nelson, K., \& Clarke, J. (2010) Transition pedagogy: A third generation approach to FYE: a case study of policy and practice for the higher education sector. The International Journal of the First Year in Higher Education, 1(1), 1-20.

Krause, K. L. (2005). Understanding and promoting student engagement in university learning communities. Centre for the Study of Higher Education, The Univeristy of Melbourne.

Kreber, C. (2013). Authenticity in and through teaching. The transformative potential of the 
scholarship of teaching. London: Routledge.

Mellor, D., Stokes, M., Firth, L., Hayashi, Y., \& Cummins, R. (2008). 'Need for belonging, relationship satisfaction, loneliness, and life satisfaction. Personality and Individual Differences. 45(3), 213-218.

Morieson, L., Carlin, D., Clarke, B., Lukas, K., Wilson, R. (2013). Belonging in education: Lessons from the belonging project. International Journal of First Year in Higher Education, 4(2), 87-96.

Ribera, A. K., Miller, A.L., \& Dumford, A.D. (2017). Sense of peer belonging and institutional acceptance in the first year: The role of high-impact practices. Journal of College Student Development, 58(4), 545-563.

Strayhorn, T. L. (2012). College Students Sense of Belonging. New York: Routledge.

Thomas, L. (2012). Building Student Engagements and Belonging in Higher Education at a Time of Change: Final report from the what works? student retention \& success programme. England: Paul Hamlyn Foundation and Higher Education Funding Council for England.

Tinto, V. (1993). Leaving College: Rethinking the causes and cures of student attrition (2nd edition). Chicago: University of Chicago Press.

Walton, G. M., Cohen, G. L., Cwir, D., \& Spence, S. J. (2011). Mere belonging: the power of social connection. Journal of Personality and Social Psychology, 102(3), 513-532. 